\title{
Arven fra Statens skjermbildefotografering (SSF)/ Statens helseundersøkelser (SHUS): En introduksjon til databanken
}

\author{
Per G. Lund-Larsen
}

\section{INNLEDNING}

Statens helseundersøkelser ble som nevnt $\mathrm{i}$ forordet per 1. januar 2002 fusjonert inn i Nasjonalt folkehelseinstitutt og sluttet derved å eksistere som egen institusjon. Personal og ansvar for diverse virksomheter ble fordelt på Folkehelseinstituttets forskjellige avdelinger innen Divisjon for administrasjon, Divisjon for smittevern og Divisjon for epidemiologi. Ansvaret for gjennomføring av pågående helseundersøkelser ble lagt til Divisjon for epidemiologi, avdeling for helseundersøkelser (EPUS) med støtte fra Divisjon for administrasjon, avdeling for drift (ADDR). Ansvar for gamle og nye SHUS/EPUS-relaterte data ble lagt til Divisjon for epidemiologi, avdeling for helsestatistikk.

Som nevnt i forordet, beskrev Kjell Bjartveit i 1997 i grove trekk SSF/SHUS's historie fra starten i 1943 til $1997^{1}$. Bjartveit sluttet sin artikkel med: "Ta vare på arvesølvet!" Sølvet han beskrev var nærmest et amalgam av fire komponenter. En av komponentene var: "standardiserte prosedyrer for alle undersokelser - med detaljerte protokoller for metodikk, og med nitid registrering og oppbevaring av resultater". Denne delen av "arvesølvet" er i økende grad blitt en nødvendighet for at lagrete data senere skal kunne brukes til statistikk og epidemiologisk forskning.

Solide helsedata blir gjerne mer verdifulle etter som tiden går, ved at man kan følge tidstrender eller ved at man ved forskjellige oppfølgninger eller koblinger kan registrere hvordan det har gått med enkeltindivider og grupper. Problemet med aldersstegne data er imidlertid at de som har inngående kjennskap til dataene også eldes og etter hvert forsvinner. Da er det viktig som Bjartveit skriver at det finnes god dokumentasjon og at denne lar seg fremskaffe. Nå i elektronikkens tidsalder hvor Giga er på billigsalg, må det være en selvfølge at alle originaldata ligger trygt lagret. Hensikten med mitt bidrag både som gjesteredaktør og med denne artikkelen, er i første rekke å forsøke å bidra til at arven fra SSF/SHUS, som nevnt $\mathrm{i}$ forordet, i størst mulig grad blir gjort kjent for det epidemiologiske miljø. Jeg håper også at noen få tekniske opplysninger kan bidra til enklere og bedre tilgang og utnyttelse av disse materialene. Denne introduksjonen vil spesielt ta for seg data/materialer fra de store hjerte-karrelaterte helseundersøkelsene foretatt siden 1974. SSF/SHUS har imidlertid, som beskrevet av Bjartveit, vært involvert i en rekke andre programmer/ prosjekter. Det tekniske opplegget for filer og doku- mentasjon vil i grove trekk ligne opplegget for hjertekarundersøkelsene.

\section{FILER OG FILBESKRIVELSER}

Etter at det 11-sifrete fødselsnummeret ble tatt i bruk i 1964-65 på grunnlag av folketellingen i 1960, har det vært en selvfølge at alle persondata i SSF/SHUS har inkludert fødselsnummer, i den grad personene det gjelder har fått tildelt et slikt nummer. Fødselsnummeret er som bekjent ordnet etter: fødselsdag, -måned, -år og personnummer, men på SHUS-filer som har vært brukt til invitasjon til helseundersøkelser, kan fødselsnummeret være formatert: år, mnd, dag, personnummer. Fødselsnummeret er unikt for en person, men det kan av forskjellige grunner bli forandret både en og flere ganger. Dersom man får tilgang til en gammel fil og skal matche denne mot en nylig oppdatert fil f.eks. over dødsårsaker, kan en del fødselsnummer ikke ha match på "dødefila" selv om personen er død, fordi personen har fått endret sitt fødselsnummer. (Personen er tilsynelatende blitt udødelig.) Gamle filer må derfor før matching til nye filer bli "kjørt" mot den såkalte Linkfilen hvorved man får byttet ut utgåtte fødselsnummer med de sist brukte. Utgåtte fødselsnummer er formelt legale og kommer ikke ut som feil ved kontroll med den vanlige fødselsnummeralgoritmen. Siden fødselsnummeret dessverre bare er på 11 siffer, ikke 13, må man som bekjent ty til en kombinasjon av år født (to siffer) og de tre første siffer i personnummeret (individnummeret) for å bestemme i hvilket århundre vedkommende ble født. Personer født 1900-1999 har alle individnummer 000-499. Personer født i 55-99 og med individnummer 500-749 er født i 1855-1899. Personer født 00-54 og med individnummer 500-999 er født i 2000-2054. Fra de senere år vil man på de originale SHUS-filene også finne et fylkesspesifikt løpenummer. Bare Folkehelseinstituttet skal kjenne koblingen til fødselsnummer. De fleste forskningsfiler er derfor bare utstyrt med løpenummer.

Filer som inneholder data som er punchet fra dokumenter som spørreskjema eller registreringskort, vil inneholde spesielle nummer som angir hvor det enkelte originaldokumentet er (eller har vært) arkivert. Spørreskjemaer står $i$ et fjernarkiv etter fylke og år. Dokumenter som er makulert skal være notert $i$ en makuleringsprotokoll.

Alle originalfiler fra SHUS foreligger som "flate" filer (ascii-format). Filene er beskrevet $\mathrm{i}$ en filbeskri- 
velse. Én linje i filbeskrivelsen angir hvilke posisjoner på filen som befinner seg i et felt, f.eks. 1-2, 3-4, 5-6 og 7-11 (når fødselsnummeret ligger først på en fil). Neste linje i filbeskrivelsen navngir hvilke data som befinner seg i feltet, f.eks. dag, mnd, år, personnummer. I linjen Pic. finner man for hvert felt et Cobol"statement" av formatet for hva som befinner seg $\mathrm{i}$ feltet. 9 står for numerisk (0-9), her skal det formelt ikke eksistere blank (det skal være satt inn 0(er)), X betyr alt annet enn strengt numerisk (blank, alfanumerisk eller blandinger). 9 eller $\mathrm{X}$ blir alltid fulgt av en parentes som angir antall posisjoner som 9 eller $\mathrm{X}$ gjelder. F.eks. 9(2) for feltet dag eller X(16) når det er satt av 16 posisjoner på filen for et navn. Desimaltegn er ikke satt inn i disse filene, men $\mathrm{V}$ betegner et ikke innsatt desimaltegn. F.eks. vil feltet for kolesterol i mmol/l være et felt med 4 posisjoner der de to første er heltall, de to siste er desimaler. Dette betegnes: 9(2)V9(2). Andre linjer i filbeskrivelsen er uvesentlige for vanlige brukere.

\section{KODEBESKRIVELSER/KODELISTER}

Svarende til hver fil/filbeskrivelse vil det foreligge en kodebeskrivelse. I en del eldre filer kan korte kodebeskrivelser være skrevet direkte på filbeskrivelsen f.eks. M, K under et en-posisjonsfelt der kjønn er kodet med bokstaver (ellers er kjønn kodet mann=1 kvinner=2). Kodelistene angir for hvert felt hvordan feltet er kodet og derved også hva som er legale tegn i feltet. I de senere helseundersøkelsene ble det stadig mer vanlig med åpne spørsmål der det etter hvert kunne bli mange svaralternativer. Dersom mulige kodealternativer ble svært omfattende vil kodelisten henvise til en separat kodebeskrivelse: "Se separat kodebeskrivelse". Slike kodebeskrivelser, inkludert spesielle koderutiner, finnes $\mathrm{i}$ et kodelistearkiv som for tiden er lokalisert på avdeling for helseundersøkelser (EPUS). For åpne spørsmål om bruk av medikamenter er det konstruert en egen database der hele systemet med ATC-koder er innlagt. For de senere store helseundersøkelser foreligger de fleste kodelister også i elektronisk form.

\section{PROSJEKTPERMER/PROTOKOLLER}

Det er en uendelighet av spørsmål som kan dukke opp når data skal analyseres og ev. publiseres. Oftest blir det spørsmål om utvalg, utstyr eller metoder som ble anvendt, hvordan blodprøvene ble håndtert eller nøyaktig formulering på spørreskjema eller samtykke. Til dette bruk er det, foreløpig i EPUS' lokaler, et prosjektperm/protokoll-arkiv (som nok kan trenge adskillig opprydning etter flytteprosessen). Her vil en, ordnet på fylke og år, finne permer med dokumenter som spørreskjema, trykksaker og en mer eller mindre fyldig teknisk protokoll der det viktigste angående utvalg, prosedyrer, målemetoder, blodprøver osv. skal være spesifisert. Det vil også for de større prosjektene være ført en logg der spesielle hendelser, avvik fra rutinene, uhell osv. er notert.

\section{Prosjektbetegnelser}

Helseundersøkelsene er betegnet med fylke og hvilken gang en slik undersøkelse er gjennomført. (Finnmark 1, 2 osv.). De store samarbeidsprosjektene har i tillegg fått navn som HUNT $1 \operatorname{og} 2$, HUSK 1 og 2, HUBRO og MoRo. Etter 2000 ble det moderne å operere med flere fylker under én betegnelse (OPPHED og TROFINN). Likevel vil det finnes separat dokumentasjon for hvert fylke, da undersøkelsene aldri ble helt identiske. I tillegg til originalfiler for hvert enkelt fylke og for hver gang en var $i$ et fylke vil det finnes forskjellige versjoner av analysefiler der data fra en rekke undersøkelser er samlet. Slike filer foreligger gjerne i SPSS format. I Appendix 1 vil en finne en kronologisk oversikt over de viktigste helseundersøkelser gjennomført til dato.

\section{SAMTYKKE}

Filer som gjelder undersøkelser etter 1992 vil inneholde et felt hvor resultatet av det skriftlige samtykket er lagt inn. Ordlyden for samtykket kan variere. Prosjektpermene skal inneholde kopi av samtykket. De fleste samtykkeerklæringer er spesifisert slik at det kan samtykkes til enkelte anvendelser av data, men ikke andre. Personer som i utgangspunktet ga et fullt samtykke kan i ettertid ha kommet med ønske om å reservere seg mot bruk av "sine" data. Samtykkefeltet i datafilene skal da være rettet opp i henhold til dette. I samtykkets "barndom" ble alle data fra personer som ikke lenger ønsket å delta, slettet. I de senere år har praksis vært bare å slette all informasjon som kan identifisere en person. Selv om det ved kreering av analysefiler og utlevering av data er tatt hensyn til samtykkene bør alle som skal anvende en SHUS-fil for sikkerhets skyld starte med å sjekke feltet for samtykke. Det er inntil videre bestemt at alle underskrevne samtykkeerklæringer skal fjernlagres.

\section{BLODPRØVER}

Helt siden SSF/SHUS begynte med de store fylkesundersøkelsene i 1974 har forskjellige blodanalyser inngått i programmet. I lange perioder har rester av serum blitt overført til JANUS serumbank som nå eies av Kreftforeningen. JANUS-banken er øremerket for kreftforskning. Totalt har SSF/SHUS levert serum til JANUS fra vel 282,000 personer. I dette materialet er det hittil registrert 20,001 tilfeller av kreft. Registeret over personer i JANUS føres av Kreftregisteret. Ved behov kobles persondata fra helseundersøkelsene til Janusmaterialet. Henvendelser om samarbeidsprosjekter sendes formannen i styringsgruppen: Professor Egil Jellum, Institutt for klinisk biokjemi, Rikshospitalet. Hittil er det også levert ca 167,000 fullblodprøver til CONOR som beskrevet av Engeland og Søgaard i dette nummeret. Mesteparten av dette blodet er lagret ved $-70^{\circ}$ i forskjellige laboratorier. Hvert laboratorium 
har en database med koordinater til lokalisasjonen for hver prøve. I tillegg til disse store "blodbankene" finnes det mindre ansamlinger av blodprodukter fra forskjellige prosjekter.

\section{MANGFOLDET}

Det ville være en formidabel oppgave å gjøre rede for alle de programmer, prosjekter og virksomheter som $\mathrm{SSF} / \mathrm{SHUS}$ i sine 59 år har vært involvert i. Fra de fleste virksomheter gjennomført etter at fødselsnummeret ble innført vil det foreligge persondata. De forskjellige referanselistene en finner i dette temanummeret og i temanummeret av Norsk Epidemiologi nr. 2 , oktober 1997, vil vise noe av mangfoldet $\mathrm{i}$ denne virksomheten. I Appendix 2 har vi listet opp det meste av de publikasjoner der SSF/SHUS tilsatte har vært involvert. Vi vil også vise til en fyldig redegjørelse for hva samarbeidet SHUS, ISM og Finnmark fylke har avstedkommet av publikasjoner ${ }^{2}$.

\section{REFERANSER}

1. Bjartveit K. Statens helseundersøkelser: Fra tuberkulosekamp til mangesidig epidemiologisk virksomhet. Norsk Epidemiologi 1997; 7 (2): 157-174.

2. Forsdahl A, et al. Hjerte-karundersøkelsene i Finnmark 1974-2000. ISM skriftserie nr. 58.

Appendix 1. Oversikt over fylkesvise helseundersøkelser.

\begin{tabular}{|c|c|c|c|}
\hline Fylke & Påbegynt & Avsluttet & Antall inviterte \\
\hline Finnmark I & 11.03 .1974 & Febr/mars 1975 & 17517 \\
\hline Oslo I & & 1976 & 30025 \\
\hline Sogn og Fjordane & 10.03 .1975 & 05.03.1976 & 16629 \\
\hline Oppland I & 15.03 .1976 & 21.02 .1978 & 31632 \\
\hline Finnmark II & 07.03.1977 & 09.03.1978 & 20683 \\
\hline Tromsø I & & 1980 & 8867 \\
\hline Tromsø II & & 1981 & 21441 \\
\hline Sogn og Fjordane II & 28.02 .1980 & 10.03 .1981 & 19508 \\
\hline Oppland II & 16.03 .1981 & 18.02 .1983 & 31582 \\
\hline Nord-Trøndelag I & 11.01 .1984 & 14.02 .1986 & 87285 \\
\hline Sogn og Fjordane III & 11.03 .1985 & 19.03.1986 & 21426 \\
\hline Østfold I & 06.11 .1985 & 30.09 .1986 & 10137 \\
\hline Oppland III & 05.03 .1986 & 27.04 .1988 & 37254 \\
\hline Aust-Agder I & 03.04 .1986 & 05.09 .1986 & 4205 \\
\hline Tromsø III & 12.08.1986 & Uke 181987 & 29028 \\
\hline Sør-Trøndelag I & 07.10 .1986 & 09.11 .1987 & 10911 \\
\hline Finnmark III & 09.03.1987 & 20.06.1988 & 23004 \\
\hline Vest-Agder I & 23.04.1987 & 30.10 .1987 & 6083 \\
\hline Hedmark I & 12.01 .1988 & 06.10 .1988 & 8719 \\
\hline Vestfold I & 02.05 .1988 & 03.10 .1988 & 9283 \\
\hline Nordland I & 18.08 .1988 & 16.03 .1989 & 11516 \\
\hline Svalbard & Sept. 1988 & Sept. 1988 & 801 \\
\hline Rogaland I & 04.10 .1988 & 26.05 .1989 & 14703 \\
\hline Østfold II & 31.10 .1988 & 28.06 .1989 & 13565 \\
\hline Hordaland & 07.11 .1988 & 27.09 .1990 & 112235 \\
\hline Aust-Agder II & 30.03 .1989 & 21.06.1989 & 5051 \\
\hline Nord-Trøndelag II & 06.06 .1989 & 13.12 .1989 & 9698 \\
\hline Telemark I & 15.08 .1989 & 11.12 .1989 & 7181 \\
\hline Sør-Trøndelag II & 16.08 .1989 & 20.04 .1990 & 13287 \\
\hline Sogn og Fjordane IV (I) & 09.01 .1990 & 02.05 .1990 & 6546 \\
\hline Møre og Romsdal I & 10.01 .1990 & 19.11 .1990 & 17172 \\
\hline Finnmark IV & 02.05 .1990 & 17.10 .1990 & 7633 \\
\hline Vest-Agder II & 07.05 .1990 & 11.10 .1990 & 7165 \\
\hline Akershus I & 23.10 .1990 & 03.09.1991 & 19827 \\
\hline
\end{tabular}




\begin{tabular}{|c|c|c|c|}
\hline Fylke & Påbegynt & Avsluttet & Antall inviterte \\
\hline Hedmark II & 08.01 .1991 & 08.05 .1991 & 7947 \\
\hline Oppland IV (I) & 08.01 .1991 & 03.10 .1991 & 13196 \\
\hline Vestfold II & 03.04 .1991 & 17.12.1991 & 8580 \\
\hline Troms I & 27.05 .1991 & 08.04 .1992 & 7002 \\
\hline Rogaland II & 25.09 .1991 & 30.04 .1992 & 14891 \\
\hline Østfold III & 07.10 .1991 & 17.06.1992 & 10306 \\
\hline Nordland II & 05.11 .1991 & 14.05 .1992 & 9898 \\
\hline Hordaland I & 02.04 .1992 & 02.04 .1993 & 24815 \\
\hline Aust-Agder III & 05.05 .1992 & 28.08 .1992 & 4253 \\
\hline Nord-Trøndelag II & 20.05 .1992 & 30.09 .1992 & 5393 \\
\hline Telemark II & 03.09 .1992 & 13.01.1993 & 8563 \\
\hline Sør-Trøndelag III & 02.10 .1992 & 01.04 .1993 & 10613 \\
\hline Buskerud I & 18.01 .1993 & 02.04 .1993 & 9731 \\
\hline Finnmark V & 14.04.1993 & 12.10 .1993 & 7410 \\
\hline Sogn og Fjordane V (II) & 03.05 .1993 & 15.09 .1993 & 4338 \\
\hline Møre og Romsdal II & 03.05 .1993 & 03.12 .1993 & 10204 \\
\hline Vest-Agder III & 20.09 .1993 & 17.12 .1993 & 5967 \\
\hline Akershus II & 26.10 .1993 & 09.09.1994 & 19809 \\
\hline Hedmark III & 04.01 .1994 & 28.04 .1994 & 7917 \\
\hline Oppland V (II) & 04.01 .1994 & 05.05 .1994 & 7532 \\
\hline Troms II & 02.05 .1994 & 30.08 .1994 & 3883 \\
\hline Vestfold III & 09.05 .1994 & 03.11 .1994 & 8881 \\
\hline Tromsø IV & 05.09 .1994 & 30.06 .1995 & 37582 \\
\hline Nordland III & 02.11 .1994 & 28.04 .1995 & 10097 \\
\hline Rogaland III & 08.11 .1994 & 22.06 .1995 & 15710 \\
\hline Aust-Agder IV & 15.05 .1995 & 18.09.1995 & 4334 \\
\hline Sør-Trøndelag IV & 07.06 .1995 & 19.01 .1996 & 10986 \\
\hline Nord-Trøndelag (HUNT) & 15.08 .1995 & 18.06 .1997 & 94197 \\
\hline Telemark III & 20.09 .1995 & 19.01.1996 & 6999 \\
\hline Sogn og Fjordane VI (III) & 24.01 .1996 & 17.04.1996 & 4402 \\
\hline Buskerud II & 24.01 .1996 & 20.06 .1996 & 9998 \\
\hline Møre og Romsdal III & 22.04 .1996 & 14.11.1996 & 10425 \\
\hline Vest-Agder IV & 13.08 .1996 & 04.11 .1996 & 6302 \\
\hline Finnmark VI & 25.11 .1996 & 09.06 .1997 & 12366 \\
\hline Hedmark IV & 12.08.1997 & 28.10 .1997 & 7892 \\
\hline Nordland IV & 01.10 .1997 & 17.03.1998 & 10161 \\
\hline Oppland V (III) & 29.10 .1997 & 27.02.1998 & 7820 \\
\hline Hordaland (HUSK) & 27.10 .1997 & 24.06.1999 & 38587 \\
\hline Akershus III & 06.11 .1997 & 09.09.1998 & 20507 \\
\hline Troms III & 11.06.1997 & 30.09 .1997 & 3914 \\
\hline Rogaland IV & 04.03 .1998 & 22.01.1999 & 20865 \\
\hline Sør-Trøndelag V & 23.03 .1998 & 08.10 .1998 & 11113 \\
\hline Aust-Agder V & 20.10 .1998 & 11.12.1998 & 4369 \\
\hline Møre og Romsdal IV & 14.01.1999 & 23.06 .1999 & 10152 \\
\hline Sogn og Fjordane VII (IV) & 27.01 .1999 & 22.04.1999 & 4432 \\
\hline Buskerud III & 27.04 .1999 & 15.10 .1999 & 10066 \\
\hline Østfold IV & 16.08.1999 & 17.12.1999 & 17483 \\
\hline \multirow[t]{2}{*}{ Vest-Agder V } & 16.09.1999 & 16.12.1999 & 6770 \\
\hline & & $\begin{array}{l}23.03 .2000 \\
\text { etter purring i Vennesla }\end{array}$ & \\
\hline Samlivsprosjektet i Vennesla & 15.12.1999 & 11.01 .2000 & 1017 \\
\hline Oslo II & 17.01 .2000 & 17.10 .2000 & 12767 \\
\hline Oslo (MoRo) & 28.02 .2000 & 23.06 .2000 & 6140 \\
\hline Oslo (HUBRO) & 04.05 .2000 & 28.09 .2001 & 58459 \\
\hline \multirow[t]{2}{*}{ Hedmark og Oppland (OPPHED) } & 15.11 .2000 & 19.04.2001 (Hedmark) & 11219 (Hedmark) \\
\hline & & 13.11.2002 (Oppland) & 22327 (begge fylkene totalt) \\
\hline Tromsø V, rest-Troms og Finnmark & 07.03 .2001 & 07.12.2001 (Tromsø) & 10420 \\
\hline
\end{tabular}


Appendix 2. Publikasjonsliste med tidligere SHUS-ansatte som forfattere.

\section{7}

1. Bjartveit K. Cardiovascular disease study in Norwegian counties. Preliminary report. Nordic Council for Arctical Medical Research Report No.19, pp 125-30, Oulu, Finland 1977.

\section{8}

2. Bjartveit K. The tuberculosis situation in Norway. Scand J Resp Dis 1978; Suppl 102: 28-35.

\section{9}

3. Bjartveit K, Foss OP, Gjervig T, Lund-Larsen PG. The cardiovascular disease study in Norwegian counties. Background and organization. Acta Med Scand 1979; Suppl 634.

4. Kvamme J-I, Haider T. Hjerte-karundersøkelsen i Finnmark - Et eksempel på en populasjons-undersøkelse rettet mot kardiovaskulære sykdommer. Beskrivelse og analyse av etterundersøkelsesgruppe. ISM skriftserie nr. 3, Universitetet i Tromsø, Institutt for samfunnsmedisin, Tromsø 1979.

5. Waaler HTh, Helgeland A, Hjort PF, Lund-Johansen P, Lund-Larsen PG, Mathisen R, Storm-Mathisen H. Høyt blodtrykk: Behandlingsprogram, utbytte, kostnader. Gruppe for helsetjenesteforskning. Rapport nr. 2, 1979.

6. National Mass Radiography Service, Health Services of Finnmark County, Central Laboratory, Ullevaal Hospital, Faculty of Medicine, University of Tromsø. The cardiovascular study in Finnmark 1974-85. Nordic Council for Arctical Medical Research Report No. 25, 1979.

\section{0}

7. Bjartveit K. Cardiovascular Disease Study in Norwegian Counties. Preliminary report. In: Geomedical Aspects in Present and Future Research (ed. Låg J), pp. 59-63. The Norwegian Academy of Science and Letters. Universitetsforlaget, Oslo 1980.

\section{1}

8. Bjartveit K. Kontroll av tuberkulose. Helsedirektoratet, Oslo 1981.

9. Bjartveit K. Controlling the epidemic: legislation and restrictive measures. Can J Public Health 1981; 72: 406-12.

10. Lund-Larsen PG, Dahlberg BE. Blodtrykk hos ansatte i spesielt varme og i vanlige avdelinger ved aluminiumssmelteverket i Årdal. Tidsskr Nor Lageforen 1981; 101: 1892.

\section{2}

11. Haider T, Tverdal A. Prevalens av tuberkulosesmitte. Tidsskr Nor Laegeforen 1982; 102 (22): 1065-8.

12. Helgeland K, Haider T, Jonsen J. Copper and zink in human serum in Norway. Scand J Clin Lab Invest 1982; 42: 35 .

13. Lund-Larsen PG, Tretli S. Changes in smoking habits and body weight after three-year-period - the cardiovascular disease study in Finnmark. J Chronic Dis 1982; 35: 773-80.

14. Tretli S, Lund-Larsen PG, Foss OP. Reliability of questionnaire information on cardiovascular disease and diabetes: cardiovascular disease study in Finnmark County. J Epidemiol Community Health 1982; 36: 269.

\section{3}

15. Bjartveit K, Foss OP, Gjervig T. The Cardiovascular Disease Study in Norwegian Counties. Results from first screening. Acta Med Scand 1983; Suppl 675: 1-184.

16. Haider T, Foss OP. The analytical variation and the mean difference of serum lipid values in duplicate samples subjected to different times of storage. Scand J Clin Invest 1983; 43: 439.

17. Lund-Larsen PG, Haider T, Tretli S, Tverdal A, Bjartveit K. Fysisk inaktivitet i fritiden blant 20-49 åringer i Oppland fylke 1976-78. Tidsskr Nor Laegeforen 1983; 103: 428.

18. Tretli S, Lund-Larsen PG, Bjartveit K. Questionnaire prevalence of cardiovascular disease and symptoms, changes of a period of three years. I: Festskrift til professor Knut Westlund på hans 60-årsdag, pp. 123-41. ISM skriftserie nr. 6, Universitetet i Tromsø, Institutt for samfunnsmedisin, Tromsø 1983. 


\section{4}

19. Statens skjermbildefotografering. Håndbok for helseundersøkelsen i Nord-Trøndelag. 4 mål i sikte. Oslo 1984.

20. Lund-Larsen PG, Waaler HTh. Medikamentell blodtrykksbehandling. Presentasjon av plansje med indikasjoner. Tidsskr Nor Lageforen 1984; 104: 283.

\section{5}

21. Tretli S, Bjartveit K, Foss OP, Haider T, Lund-Larsen PG. Intervention on cardiovascular disease risk factors in Finnmark county, Norway. Scand J Soc Med 1985; 13: 401.

22. Hilt B, Langård S, Lund-Larsen PG, Lien JT. Asbesteksponering og asbestbetingede lungefunn. En tversnittsundersøkelse i Telemark. Tidsskr Nor Lageforen 1985; 105 (19-21): 1318-21.

\section{6}

23. Hilt B, Lien JT, Lund-Larsen PG, Lund K, Langård S. Asbestos-related findings in chest radiographs of the male population of the county of Telemark, Norway, - a cross-sectional study. Scand J Work Environ Health 1986; 12 (6): 567-73.

24. Hilt B, Langård S, Lund-Larsen PG, Lien JT. Previous asbestos exposure and smoking habits in the county of Telemark, Norway, - a cross-sectional population study. Scand J Work Environ Health 1986; 12 (6): 561-6.

25. Tverdal A. Body mass index and incidence of tuberculosis. Eur J Resp Dis 1986; 69: 355-62.

26. Bjartveit K. Effect of intervention on coronary heart disease risk factors in some Norwegian counties. Am J Med 1986; 80 (Suppl 2A): 12.

27. Thürmer H, Bjartveit K. Norske legers røykevaner 1952-84. Konsekvenser for pasientinformasjon. Tidsskr Nor Lageforen 1986; 106 (34-36): 2961-5.

28. Bjartveit K. Legislation and political activity. Reprinted from Tobacco: A major international health hazard. IARC Scientific Publications No. 74, 1986.

29. Foss OP, Lund-Larsen PG. Serum thiocyanate and smoking: interpretation of serum thiocyanate levels observed in a large health study. Scand J Clin Lab Invest 1986; 46: 245.

\section{7}

30. Gulsvik A, Tverdal A, Risan E, Holm A-M, Jentoft HF, Bjartveit K. Notification of tuberculosis in the southwest health region of Norway: Incidence and trends. Br J Dis Chest 1987; 81: 140-6.

31. Statens helseundersøkelser. Håndbok for hjerte-karundersøkelsen. 40 åringsprosjektet. Oslo 1987.

32. Tverdal A. Systolic and diastolic blood pressure as predictors of coronary heart disease in middle aged Norwegian men. BMJ 1987; 294: 671-3.

33. Jellum E, Andersen A, Ørjasether H Foss OP, Lund-Larsen PG, Theodorsen L. The Janus serumbank and early detection of cancer. Biochem Clin 1987; 11: 191-5.

34. Hilt B, Lien JT, Lund-Larsen PG. Lung function and respiratory symptoms in subjects with asbestos-related disorders: a cross-sectional study. Am J Ind Med 1987; 11 (5): 517-28.

\section{8}

35. Lund-Larsen PG, Gram IT. Mammografiscreening i Tromsø. Rapport fra Statens helseundersøkelser 1988.

36. Tverdal A, Funnemark E. Protective effect of BCG vaccination in Norway 1956-73. Tubercle 1988; 68: 11923.

37. The cardiovascular disease study in Norwegian counties. Results from second screening. National Health Screening Service, Oslo 1988.

38. Tverdal A. Height, weight and incidence of tuberculosis. Bull Int Union Tuberc Lung Dis 1988; 63 (2): 16-8.

39. Bjartveit K. Children - in the midst of a battlefield. Bull Int Union Tuberc Lung Dis 1988; 63 (2): 45-6.

40. SHUS-NOTAT 1/88. A note on seasonal variation of blood lipids and blood pressure in the cardiovascular disease study in Norwegian counties. National Health Screening Service, Oslo 1988. 


\section{9}

41. Gram IT, Lund-Larsen PG, Rosenlund AF, Størmer J. Mammografiscreening i Tromsø. Gjennomføring og resultat av den første mammografiscreening i Norge. Tidsskr Nor Lageforen 1989; 109 (10): 1040-2.

42. Tverdal A, Foss OP, Leren P, Holme I, Lund-Larsen PG, Bjartveit K. Serum triglycerides as an independent risk factor for death from coronary heart disease in middle-aged Norwegian men. Am J Epidemiol 1989; 129: 458-65.

43. Stensvold I, Tverdal A, Foss OP. The effect of coffee on blood lipids and blood pressure. Results from a Norwegian cross-sectional study, men and women, 40-42 years. J Clin Epidemiol 1989; 42: 877-84.

44. Tverdal A. A mortality follow-up of persons invited to a cardiovascular disease study in five areas in Norway. National Health Screening Service, Oslo 1989 (doktoravhandling).

45. Crofton J, Bjartveit K. Smoking as a risk factor for chronic airways disease. Chest 1989; 96 (3 Suppl): 307S$12 \mathrm{~S}$.

46. Solvoll K, Selmer R, Løken E, Foss OP, Trygg K. Coffee, dietary habits, and serum cholesterol among men and women 35-49 years of age. Am J Epidemiol 1989; 129: 1277-88.

47. Glattre E, Thomassen Y, Thoresen SØ, Haldorsen T, Lund-Larsen PG, Theodorsen L, Aaseth J. Prediagnostic serum selenium in a case-control study of thyroid cancer. Int J Epidemiol 1989; 18 (1): 45-9.

48. SHUS-NOTAT 1/89. A note on the epidemiology of blood pressure treatment in Norway. National Health Screening Service, Oslo 1989.

49. SHUS-NOTAT 2/89. Prediction based on one or two measurements of a variable. National Health Screening Service, Oslo 1989.

\section{0}

50. Tverdal A, Stensvold I, Solvoll K, Foss OP, $\underline{\text { Lund-Larsen PG }}$ Bjartveit K. Coffee consumption and death from coronary heart disease in middle-aged Norwegian men and women. BMJ 1990; 300: 566-9.

51. Selmer R, Foss OP, Lund-Larsen PG. Reliability of the Reflotron in the determination of cholesterol. Scand $J$ Clin Lab Invest 1990; 50: 261-71.

52. Thelle DS. Hvorfor er dødeligheten av hjerteinfarkt fallende i Norge? Tidsskr Nor Lageforen 1990; 111: 2049-50.

53. Selmer R. A comparison of Poisson regression models fitted to multiway summary tables and Cox survival model using data from a blood pressure screening in the city of Bergen, Norway. Stat Med 1990; 9: 1157-65.

54. Thürmer H, Lund-Larsen PG, Tverdal A, Thelle DS. Treatment of hypertension as a risk factor in a prospective study. Int J Risk Safety Med 1990; 1: 267-78.

55. Holmen J, Midthjell K, Bjartveit K, Hjort PF, Lund-Larsen PG, Moum T, Næss S, Waaler HTh. The NordTrøndelag Health Survey 1984-86. Helsetjenesteforskning, Report No. 4, Senter for samfunnsmedisinsk forskning, Verdal 1990.

\section{1}

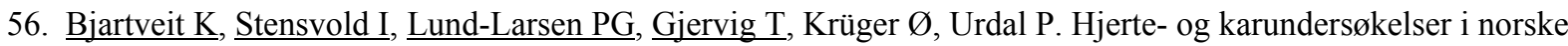
fylker. Bakgrunn og gjennomføring. Status 1986-90 for risikomønster blant 40-42 åringer i 14 fylker. Tidsskr Nor Loegeforen 1991; 111: 2063-72.

57. Bjartveit K, Stensvold I, Lund-Larsen PG, Graff-Iversen S, Urdal P. Hjerte- og karundersøkelser i norske fylker. Utvikling 1985-90 av risikomønster blant 40-42 åringer i fire fylker. Tidsskr Nor Lageforen 1991; 111: 2072-6.

58. Seim A, Myran AH, Graff-Iversen S. Forebygging av hjerte- og karsykdommer i Rissa. Tidsskr Nor Loegeforen 1991; 111: 2078-80.

59. Tambs K, Moum T, Eaves L, Neale M, Midthjell K, Lund-Larsen PG, Næss S, Holmen J. Genetic and environmental contributions to the variance of the body mass index in a Norwegian sample of first- and second-degree relatives. Am J Hum Biol 1991; 3: 257-67.

60. Thelle DS. Er blodtrykksbehandlingen farligere enn sitt rykte? Tidsskr Nor Lageforen 1991; 111 (1): 14-5.

61. Graff-Iversen S, Holm HA, Istad H, Ose L, Rom AK, Kristiansen IS, Thelle DS, Torsvik H, Urdal P, Wiik J. Behandling av hyperkolesterolemi hos voksne. Handlingsprogram 1991. Tidsskr Nor Laegeforen 1991; 111: 3407-11.

62. Graff-Iversen S, Thürmer H, Valbø AL. Hvorfor røyker kvinner, når menn slutter? Tidsskr Nor Loegeforen 1991; 111: 3521-3. 
63. National Health Screening Service, Oslo, Health Services of Nord-Trøndelag County, Ullevål Hospital, Central Laboratory, Oslo. The cardiovascular disease survey in Nord-Trøndelag, 1989. Oslo 1991.

64. Meyer HE. Osteoporose - epidemiologiske aspekter og risikofaktorer. Norsk Tidsskrift for Geriatri 1991; 4: 5-7 (oversiktsartikkel).

\section{2}

65. Krüger $\emptyset$, Graff-Iversen S, Stensvold I. Risikofaktorer og dødelighet av hjerteinfarkt i Kristiansund, Ålesund og Molde. Tidsskr Nor Laegeforen 1992; 112: 1609-13.

66. Stensvold I, Tverdal A, Solvoll K, Foss OP. Tea consumption. Relationship to cholesterol, blood pressure, and coronary and total mortality. Prev Med 1992; 21: 546-53.

67. Stensvold I, Urdal P, Thürmer H, Tverdal A, Lund-Larsen PG, Foss OP. High-density lipoprotein cholesterol and coronary, cardiovascular and all cause mortality among middle-aged Norwegian men and women. Eur Heart J 1992; 13: 1155-63.

68. Tambs K, Moum T, Holmen J, Eaves LJ, Neale MC, Lund-Larsen PG, Næss S. Genetic and environmental effects on blood pressure in a Norwegian sample. Genet Epidemiol 1992; 9: 11-26.

69. Tambs K, Moum T, Eaves LJ, Neale MC, Midthjell K, Lund-Larsen PG, Næss S. Genetic and environmental contributions to the variance of body height in a sample of first and second degree relatives. Am J Phys Anthropol 1992; 88: 285-94.

70. Jacobsen BK, Stensvold I, Fylkesnes K, Kristiansen IS, Thelle DS. The Nordland health study. Scand J Soc Med 1992; 20 (3): 184-7.

71. Jacobsen BK, Stenvold I. Milk - a better drink? Relationships with total serum cholesterol in a cross-sectional survey. The Nordland health study. Scand J Soc Med 1992; 20: 204-8.

72. Midthjell K, Holmen J, Bjørndal A, Lund-Larsen PG. Is questionnaire information valid in the study of a chronic disease such as diabetes? The Nord-Trøndelag diabetes study. J Epidemiol Community Health 1992; 46: $537-42$.

73. Selmer R. Blood pressure and twenty-year mortality in the city of Bergen, Norway. Am J Epidemiol 1992; 136: $428-40$.

74. Graff-Iversen S, Gjervig T, Lund-Larsen PG, Hjemmen A, Dalgard OS, Holmsen E. Sosialt nettverk, alkoholvaner og voldskader hos kvinner og menn i Akershus fylke. Resultater fra anonym spørreundersøkelse blant 40-42 åringer 1990-91. Tidsskr Nor Lageforen 1992; 112: 3579-83.

\section{3}

75. Glattre E, Haldorsen T, Berg JP, Stensvold I, Solvoll K. Norwegian case-control study testing the hypothesis that seafood increases the risk of thyroid cancer. Cancer Causes Control 1993; 4: 11-6.

76. Thürmer H. Risk factors for, and 13-year mortality from cardiovascular disease by socioeconomic status. Institute of Community Medicine, Tromsø, Norway, 1993 (doktoravhandling).

77. Tverdal A, Thelle DS, Stensvold I, Leren P, Bjartveit K. Mortality in relation to smoking history: 13 years' follow-up of 68,000 Norwegian men and women 35-49 years. J Clin Epidemiol 1993; 46 (5): 475-87.

78. Meyer HE, Tverdal A, Falch JA. Risk factors for hip fracture in middle-aged Norwegian women and men. Am J Epidemiol 1993; 137 (11): 1203-11.

79. Stensvold I, Tverdal A, Urdal P, Graff-Iversen S. Non-fasting serum triglyceride concentration and mortality from coronary heart disease and any cause in middle aged Norwegian women. BMJ 1993; 307: 1318-22.

80. Tambs K, Eaves LJ, Moum T, Holmen J, Neale MC, Næss S, Lund-Larsen PG. Age-specific genetic effects for blood pressure. Hypertension 1993; 22: 789-95.

81. Jellem E, Andersen A, Lund-Larsen PG, Theodorsen L, Ørjasæter H. The Janus serum bank. The Norwegian Cancer Society, Oslo, Norway. Sci Total Environ 1993; 139/140: 527-35.

\section{4}

82. Thürmer $\mathrm{H}$, Lund-Larsen PG, Tverdal A. Is blood pressure treatment as effective in a population setting as in controlled trials? Results from a prospective study. J Hypertension 1994; 12: 481-90.

83. Weusten-Van der Wouw MPME, Katan MB, Viani R, Huggett AC, Liardon R, Lund-Larsen PG, Thelle DS, Ahola I, Aro A, Meyboom S, Beynen AC. Identity of the cholesterol-raising factor from boiled coffee and its effects on liver function enzymes. J Lipid Res 1994; 35: 721-33.

84. Meland E, Lærum E, Stensvold I. Assessment of coronary heart disease risk, I. A postal inquiry among primary care physicians. Family Practice 1994; 11: 117-21. 
85. Stensvold I, Jacobsen BK. Coffee and cancer. A prospective study of 43000 Norwegian men and women, 3554 years. Cancer Causes Control 1994; 5: 401-8.

86. Stensvold I, Jacobsen BK. Kaffekonsum og kreftinsidens. Norsk Epidemiologi 1994; 4 (2): 60-5.

87. Thürmer H, Lund-Larsen PG, Tverdal A. Er blodtrykksbehandling like effektivt i befolkningen som i kontrollerte forsøk? Tidsskr Nor Laegeforen 1994; 114 (24): 2835-9.

88. Bjerke Karlsen K, Graff-Iversen S, Knapskog A-B. Almennpraktikerens tiltak ved høy risiko for hjertekarsykdom. Tidsskr Nor Lageforen 1994; 114 (29): 3427-30.

89. Forsén L, Bjørndal A, Bjartveit K, Edna T-H, Holmen J, Jessen V, Westberg G. Interaction between current smoking, leanness, and physical inactivity in the prediction of hip fracture. J Bone Miner Res 1994; 9 (11): 1671-8.

90. Selmer R, Tverdal A. Mortality from stroke, coronary heart disease and all causes related to blood pressure and length of follow-up. Scand J Soc Med 1994; 22 (4): 273-82.

91. Lund-Larsen PG. ECG in health and disease. ECG findings in relation to CHD risk factors, constitutional variables and 16-year mortality in 2990 asymptomatic Oslo men aged 40-49 years in 1972. The Oslo Study. ISM skriftserie nr. 30, 1994 (doktoravhandling).

92. Vatten LJ, Holmen J, Krüger Ø, Forsén L, Tverdal A. Low blood pressure and mortality in the elderly: A 6year follow-up of 18,022 Norwegian men and women age 65 years and older. Epidemiology 1994; 6 (1): 70-3.

\section{5}

93. Romanus V, Tala E, Blöndal T, Heldal E, Poulsen S. Tuberkulos-bekämpning i Norden. Nord Med $1995 ; 110$ (2): 45-7.

94. Heldal E. Resistant tuberculosis in Norway. Norsk Epidemiologi 1995; 5 (2): 37.

95. Heldal E. Underrapportering av tuberkulose. Norsk Epidemiologi 1995; 5: 15-17.

96. Hilt B, Hillerdal G, Lund-Larsen PG, Lien JT, Langård S. Asbestos-related radiographic changes by ILO classification of $10 \times 10 \mathrm{~cm}$ chest x-rays in a screening of the general population. J Occup Med 1995; 37 (2): 189-93.

97. Stensvold I, Tverdal A. The relationship of coffee consumption to various self-reported cardiovascular events in middle-aged Norwegian men and women. Scand J Soc Med 1995; 23: 103-9.

98. Meyer HE, Tverdal A, Falch J. Body height, Body mass index, and fatal hip fractures. Epidemiology 1995; 6: 299-305.

99. Selmer R, Tverdal A. Body mass index and cardiovascular mortality at different levels of blood pressure. A prospective study of Norwegian men and women. J Epidemiol Community Health 1995; 49: 265-70.

100. Meyer HE, Tverdal A, Falch JA. Changes in body weight and incidence of hip fracture among middle aged Norwegians. BMJ 1995; 311: 91-2.

101. Jellum E, Andersen A, Lund-Larsen PG, Theodorsen L, Ørjasæter H. Experiences of the Janus Serum Bank in Norway. Environ Health Perspect 1995; 103 (Suppl 3): 85-8.

102. Heldal E, Bjartveit K, Tverdal A. Utviklingen av tuberkulose i Norge - har nedgangen stanset? Tidsskr Nor Logeforen 1995; 115: 3390-3.

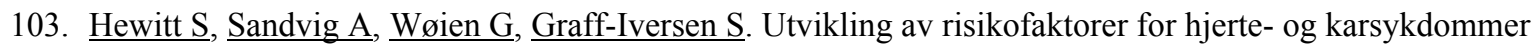
hos 40-42 åringer i Finnmark fylke 1973-93. Tidsskr Nor Lageforen 1995115 (30): 3719-23.

104. Nygård O, Vollset SE, Refsum H, Stensvold I, Tverdal A, Nordrehaug JE, Ueland PM, Kvåle G. Total plasma homocysteine and cardiovascular risk profile. The Hordaland homocysteine study. JAMA 1995; 274 (19): 1526-33.

105. Bjartveit K. Kjeldsens kritikk av Statens helseundersøkelser. Hjerteforum 1995; 8: 28-31.

106. Meyer HE, Henriksen C, Falch JA, Pedersen JI, Tverdal A. Risk factors for hip fracture in a high incidence area: a case-control study from Oslo, Norway. Osteoporosis Int 1995; 5: 239-46.

107. Meyer HE, Falch JA, O'Neill T, Tverdal A, Varlow J and The European Vertebral Osteoporosis Study Group. Height and body mass index in Oslo, Norway, compared to other regions of Europe: do they explain differences in the incidence of hip fracture? Bone 1995; 17: 347-50.

108. Bjartveit K. Den største utfordring til forebyggende helsearbeid. Norsk Epidemiologi 1995; 2: 93-106.

109. Krüger $\varnothing$, Stensvold I, Tverdal A, Thelle DS. Does consumption of boiled coffee explain regional differences in ischaemic heart disease mortality in Norway? Norsk Epidemiologi 1995; 5 (2 Suppl): 26. 
110. Tverdal A. Røyking og hjerte-kardødelighet. Norsk Epidemiologi 1995; 2: 115-20.

111. Tverdal A. Er blodtrykksbehandling like effektiv i befolkningen som kontrollerte forsøk? Hjerteforum 1995; 8 (1): $33-5$.

112. Nygård O, Vollset SE, Kvåle G, Stensvold I, Ueland PM, Refsum H. Plasma-homocystein og forbruk av kaffe og te. Norsk Epidemiologi 1995; 5 (2 Suppl): 27.

113. Prospective Studies Collaboration (incl. Bjartveit B, Stensvold I, Tverdal A). Cholesterol, diastolic blood pressure, and stroke: 13000 strokes in 450000 people in 45 prospective cohorts. Lancet 1995; 346: 164753.

114. Thürmer H, Tverdal A, Lund-Larsen PG. Er blodtrykksbehandling like effektivt i befolkningen som i kontrollerte forsøk? Tidsskr Nor Lageforen 1995; 115: 102-3.

\section{6}

115. Andersen B, Graff-Iversen S. Lavere totalkolesterol hos norske 40-42 åringer. Lipidforum 1996; 15: 23-5.

116. Njølstad I, Arnesen E, Lund-Larsen PG. Smoking, serum lipids, blood pressure, and sex differences in myocardial infarction. A 12-year follow-up of the Finnmark study. Circulation 1996; 93 (3): 450-6.

117. Stensvold I, Tverdal A, Jacobsen BK. Cohort study of coffee intake and death from coronary heart disease over 12 years. BMJ 1996; 312: 544-5.

118. Meyer H. Risk factors for hip fracture - Epidemiological studies in middle-aged and old Norwegian women and men. National Health Screening Service, Oslo 1996 (doktoravhandling).

119. Stensvold I. Coffee and health. Is high coffe consumption a risk factor for cardiovascular disease or cancer? National Health Screening Service, Oslo 1996 (doktoravhandling).

120. Stensvold I. Beskytter moderat alkoholforbruk mot hjerte-karsykdom? Norsk Epidemiologi 1996; 6: 69-76.

121. Heldal E, Naalsund A, Kongerud J, Tverdal A, Boe J. Deaths from active tuberculosis: can we rely on notification and mortality figures? Tubercle Lung Dis 1996; 77: 215-9.

122. Selmer R, Tverdal A. Changes in blood pressure as a predictor of coronary heart disease and stroke mortality: a 27-year follow-up of 15518 men and women in the City of Bergen, Norway. J Epidemiol Biostat 1996; 1: 41-50.

123. Thorvik E, Eikeland K, Stensvold I, Aursnes I. Present and future use of cholesterol-lowering drugs. Treatment of hyperlipidemia (workshop), Läkemedelsverket 1996; 2: 147-60.

124. Meyer HE, Tverdal A, Henriksen C, Pedersen JA. Risikofaktorer for lårhalsbrudd i Oslo. Tidsskr Nor Loegeforen 1996; 22: 2656-9.

125. Njølstad I, Arnesen E, Lund-Larsen PG. Body height, cardiovascular risk factors, and risk of stroke in middle-aged men and women: A 14-year follow-up of the Finnmark study. Circulation 1996; 94: 2877-82.

126. Graff-Iversen $\mathrm{S}$, Tverdal A, Stensvold I. Cardiovascular risk factors in Norwegian women using oral contraceptives: Results from a cardiovascular health screening 1985-88. Contraception 1996; 53: 337-44.

127. Urgert R, Weusten-van der Wouw MPME, Hovenier R, Lund-Larsen PG, Katan MB. Chronic consumers of boiled coffee have elevated serum levels of lipoprotein(a). J Int Med 1996; 240: 367-71.

128. Tverdal A. Høyde, vekt og kroppsmasseindeks for menn og kvinner i alderen 40-42 år. Tidsskr Nor Loegeforen 1996; 116: 2152-6.

129. Graff-Iversen S. Helse, helsevaner og serumlipider hos kvinner som brukte østrogen ved overgangsalderen $\mathrm{i}$ 1985-88. Norsk Epidemiologi 1996; 6: 21 (Abstract).

\section{7}

130. Sandvig A, Hewitt S, Wøien G, Graff-Iversen S, Lien L. Risikofaktorer for hjerte- og karsykdommer hos 4042-åringer i Hedmark fylke 1988-94. Tidsskr Nor Loegeforen 1997; 117: 2325-8.

131. Nygård O, Refsum H, Ueland PM, Stensvold I, Nordrehaug JE, Kvåle G, Vollset SE. Coffee consumption and plasma total homocysteine: The Hordaland Homocysteine Study. Am J Clin Nutr 1997; 65: 136-43.

132. Meyer HE, Pedersen JI, Løken EB, Tverdal A. Dietary factors and the incidence of hip fracture in middleaged Norwegians. Am J Epidemiol 1997; 145: 117-23.

133. Selmer R. The Bergen Blood Pressure Study - methodological and long-term outcome. National Health Screening Service, Oslo 1997 (doktoravhandling). 
134. Tverdal A. Cohort study of ethnic group and cardiovascular and total mortality over 15 years. J Clin Epidemiol 1997; 50: 719-23.

135. Heldal E, Cruz JR, Arnadottir T, Tardencilla A, Enarson DA. Successful management of a National Tuberculosis Programme under conditions of war. Int J Tuberc Lung Dis 1997; 1 (1): 16-24.

136. Statens helseundersøkelser, Fylkeslegen i Østfold, Fylkeslegen i Aust-Agder: Helseundersøkelsene i Østfold 1985 og 1988 og i Aust-Agder 1986 og 1989. Statens helseundersøkelser, Oslo 1997.

137. Bjartveit K. Statens helseundersøkelser. Fra tuberkulosekamp til mangesidig epidemiologisk virksomhet. Norsk Epidemiologi 1997; 7 (2): 157-174.

138. Meyer HE. Lårhalsbrudd og kroppshøyde. Norsk Epidemiologi 1997; 7 (2): 175-8.

139. Njølstad I, Arnesen E, Lund-Larsen PG. Røyking - en viktig risikofaktor for hjerteinfarkt blant middelaldrende kvinner og menn. En 12-års oppfølging av Finnmarksundersøkelsen. Norsk Epidemiologi 1997; 7 (2): 183-9.

140. Westlund K. Familiespørsmål i hjerte-karundersøkelsene. Norsk Epidemiologi 1997; 7 (2): 209-12.

141. Selmer R, Tverdal A. Cardiovascular abnormalities on chest x-rays as predictor of cardiovascular and total mortality. A 27-year follow-up of 42,186 men and women in the city of Bergen, Norway (In thesis 1997).

142. Selmer RM. Ekteskapelig status, risikofaktorer og dødelighet av hjerte-karsykdommer og alle årsaker. En 18-års dødelighetsoppfølging av 28170 menn og 26235 kvinner i Finnmark, Oppland og Sogn og Fjordane. Norsk Epidemiologi 1997; 7 (2): 213-9.

143. Nygård O, Refsum H, Ueland PM, Tverdal A, Vollset SE. Homocystein og livsstil. Resultater fra Homocysteinundersøkelsen i Hordaland 1992-1993. Norsk Epidemiologi 1997; 7 (2): 221-4.

144. Heldal E. Resultat av tuberkulosebehandling i Norge 1995. Norsk Epidemiologi 1997; 7 (2): 231-3.

145. Lund-Larsen PG. Blodtrykk målt med kvikksølvmanometer og med Dinamap under feltforhold - en sammenligning. Norsk Epidemiologi 1997; 7 (2): 235-41.

146. Thürmer H, Lund-Larsen PG, Stensvold I, Mikalsen JI. Blodtrykk målt ved hjerte/kar-undersøkelse i Balsfjord, av lege på kontoret, og av 40-åringer selv hjemme. Norsk Epidemiologi 1997; 7 (2): 249-54.

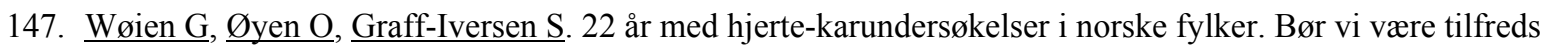
med den utviklingen risikofaktorene har hatt? Norsk Epidemiologi 1997; 7 (2): 255-66.

148. Skåra BB, Graff-Iversen S. Endring av helsevaner - for helsens skyld eller for å gå ned i vekt? Norsk Epidemiologi 1997; 7 (2): 267-71.

149. Tverdal A, Åsberg A, Bønaa KH, Stensvold I, Grudt G, Ingebretsen OC, Urdal P. Sammenligning av to blodprøver fra samme person analysert ved to laboratorier. Norsk Epidemiologi 1997; 7 (2): 283-6.

\section{8}

150. Tverdal A. Dødelighet av hjerteinfarkt i fylker og helseregioner i perioden 1951-94. Norsk Epidemiologi 1998; 8 (1): 79-90.

151. Graff-Iversen S, Stensvold I, Lund-Larsen PG, Nodarse LO, Tverdal A, Urdal P. Serum lipids in postmenopausal or perimenopausal women using estrogen alone, estrogen with levonorgestrel, or estrogen with norethisterone, compared with nonusers: results from a cross-sectional study in two Norwegian counties 1985-1988. J Clin Epidemiol 1998; 51 (2): 1311-6.

152. Meyer HE, Tverdal A, Selmer R. Weight variability, weight change, and the incidence of hip fracture: A prospective study in 39,000 middle-aged Norwegians. Osteoporosis Int 1998; 8: 373-8.

153. Jenum AK, Stensvold I, Bjartveit K, Thelle DS, Hjermann I. Risikofaktorer for hjerte- og karsykdom i Oslo, Sogn og Fjordane og Finnmark. Tidsskr Nor Lageforen 1998; 118: 18-22.

154. Njølstad I, Arnesen E, Lund-Larsen PG. Cardiovascular diseases and diabetes mellitus in different ethnic groups: The Finnmark Study. Epidemiology 1998; 9 (5): 550-6.

\section{9}

155. Meyer HE, Selmer R. Income, education level, and body height. Ann Hum Biol 1999; 26: 219-27.

156. Hoddevik GH, Selmer R. Kroniske ryggsmerter hos 40-åringer i 12 norske fylker. Tidsskr Nor Laegeforen 1999; 15: 2224-8.

157. Forsén L, Søgaard AJ, Meyer HE, Edna TH, Kopjar B. Survival after hip fracture: Short- and long-term excess mortality according to age and gender. Osteoporosis Int 1999; 10: 73-8. 
158. Forsén L, Meyer HE, Midthjell K, Edna TH. Diabetes mellitus and the incidence of hip fracture. Results from the Nord-Trøndelag Health Survey. Diabetologia 1999; 42: 920-5.

159. Kvaavik E, Meyer HE, Selmer RM, Egeland G. Tverdal A. Kostvaner i Hedmark i forhold til kjønn, utdanning og sivilstand. Tidsskr Nor Lageforen 1999; 119: 3406-9.

160. Midthjell K, Krüger Ø, Holmen J, Tverdal A, Claudi T, Bjørndal A, Magnus P. Rapid changes in the prevalence of obesity and known diabetes in an adult Norwegian population. The Nord-Trondelag Health Surveys: 1984-1986 and 1995-1997. Diabetes Care 1999; 22 (11): 1813-20.

161. Meyer HE. Beinskjørhet og brudd. Kvinners helse i Norge, NOU 1999:13, side 419-23.

162. Forsén L, Meyer HE, Søgaard AJ, Næss S, Schei B, Edna TH. Mental distress and risk of hip fracture. $J$ Epidemiol Community Health 1999; 53: 343-7.

163. Selmer R. Nedgang i saltforbruket i den norske befolkning; hvilke konsekvenser kan det få for sykelighet, dødelighet og samfunnsøkonomien? Rapport nr. 5/98. Statens råd for ernæring og fysisk aktivitet.

164. Selmer R. Hjerneslag - forekomst og mulighet for å forebygge. Kvinners helse i Norge, NOU 1999:13, 4049.

165. Tverdal A. Calculation of risk for the development of acute myocardial infarction in the normal population based on long-term follow-up studies: smokers compared with non-smokers. J Cardiovasc Risk 1999; 6: 287-91.

166. Döcker HJ. Risk factors in the development of tuberculosis in Norwegians. Rapport. Statens helseundersøkelser 1999.

167. Prospective Studies Collaboration. Collaborative overview ("meta-analysis") of prospective observational studies of the associations of usual blood pressure and usual cholesterol levels with common causes of death: protocol for the second cycle of the Prospective Studies Collaboration. J Cardiovasc Risk 1999; 6: 315-20.

\section{0}

168. Heldal E, Döcker H, Caugant DA, Tverdal A. Pulmonary tuberculosis in Norwegian patients. The role of reactivation, re-infection and primary infection assessed by previous mass screening data and restriction fragment length polymorphism analysis. Int J Tuberc Lung Dis 2000; 4: 300-7.

169. Meyer HE, Tverdal A, Falch JA, Pedersen JI. Factors associated with mortality after hip fracture. Osteoporosis Int 2000; 11: 228-32.

170. Heldal E, Tverdal A, Caugant DA, Sandven P, Enarson DA, Kongerud J. Few RFLP clusters of tuberculosis cases with both immigrants and natives in Norway. Abstract til møte i TSRU (Tuberculosis Surveillance and Research Unit), mai 2000.

171. Heldal E. Health for all in the year 2000 - Alma Ata and global tuberculosis control. NIHA-nytt 2000.

172. Tverdal A. Brystkreftdødelighet i Norge og England. Tidsskr Nor Loegeforen 2000; 120: 2703 (korrespondanse).

173. Selmer RM, Kristiansen IS, Haglerød A, Graff-Iversen S, Larsen HK, Meyer HE, Bønaa KH, Thelle DS. Cost and health consequences of reducing the population intake of salt. J Epidemiol Community Health 2000; 9: 697-702.

174. Selmer RM. Helsemessige og økonomiske konsekvenser av tobakksrøyking. NOU 2000:16 (Rapport).

175. Tverdal A. Body mass index and total mortality according to physical activity in Norwegian men. Norsk Epidemiologi 2000: 10 (Suppl 2).

176. Nordsletten L, Osnes EK, Lofthus CM, Falch J, Meyer HE. More refracture with the Gamma-nail than with a sliding screw in pertrochanteric fractures. Abstract. American Academy of Orthopaedic Surgeons 67th Annual Meeting, March 2000.

177. Johnsen N, Meyer HE, Heldal E, Bjune G. Tuberculosis in refugees and asylum seekers in Norway. Abstract (poster). $1^{\text {st }}$ Congress of IUATLD, European Region in association with the $51^{\text {st }}$ Congress of the Hungarian Respiratory Society. Budapest 12-15 April 2000.

178. Falch JA, Lofthus CM, Osnes EK, Kaastad TS, Kristiansen IS, Nordsletten L, Stensvold I, Meyer HE. Incidence of hip fractures in Oslo, Norway: No change during the last decade. Abstract. World Congress on Osteoporosis 2000.

179. Meyer HE, Tverdal A, Falch JA, Pedersen JI. Factors associated with mortality after hip fracture. Osteoporosis Int 2000; 11: 228-32. 
180. Meyer HE, Falch JA, Kvaavik E, Smedshaug GB, Tverdal A, Pedersen JI. Can vitamin D supplementation reduce the risk of fracture in the elderly? A randomized controlled trial. Abstract (muntlig presentasjon). World Congress on Osteoporosis.

181. Meyer HE, Søgaard AJ, Tverdal A. Body mass index and total mortality according to physical activity in Norwegian men. Abstract, The first Nordic conference in Epidemiology, Bergen June 2000. Norsk Epidemiologi 2000; 10 (Suppl 2): 30.

182. Vollset SE, Refsum H, Irgens LM, Emblem BM, Tverdal A, Gjessing HK, Monsen ALB, Ueland PM. Plasma total homocysteine, pregnancy complications and adverse outcomes: The Hordaland Homocysteine Study. Am J Clin Nutr 2000; 71: 962-8.

183. Jacobs DR Jr, Meyer HE, Solvoll K. Lower mortality among whole grain bread eaters in men and women in the Norwegian County Study. Abstract, The first Nordic conference in Epidemiology, Bergen June 2000. Norsk Epidemiologi 2000; 10 (Supp1 2): 29.

184. Flugsrud GB, Espehaug B, Havelin LI, Nordsletten L, Meyer HE. Body mass index and physical activity as risk factors for primary coxarthrosis. A cohort study in 50000 persons. Abstract, Nordisk Ortopedisk forening I Tampare, Finland 7-10 juni 2000.

185. Heldal E. Tuberculosis in Norway. EpiNorth 2000; 1: 50-3.

186. Egeland GM, Meyer HE, Selmer R, Tverdal A, Vollset SE. Do smokers benefit from omega-3 fatty acids? Congress for Circumpolar Health 2000.

187. Kvaavik E, Meyer HE, Smedshaug GB, Falch JA, Tverdal A, Pedersen JI. Intervensjonsstudien "Forebyggelse av lårhalsbrudd". Metode og praktisk gjennomføring. Norsk Epidemiologi 2000; 10: 79-85.

\section{1}

188. Jacobs DR Jr, Meyer HE, Solvoll K. Reduced mortality among whole grain bread eaters in men and women in the Norwegian County Study. Eur J Clin Nutr 2001; 55: 137-43.

189. Osnes EK, Lofthus CM, Falch J, Meyer HE, Stensvold I, Kristiansen IS, Nordsletten L. More postoperative femoral fractures with the Gamma-nail than the sliding screw plate in the treatment of trochanteric fractures. Acta Orthop Scand 2001; 72: 252-6.

190. Egeland GM, Meyer HE, Selmer R, Tverdal A, Vollset SE. Cod liver oil consumption, smoking, and coronary heart disease mortality: Three counties, Norway. Int J Circumpolar Health 2001; 60: 143-9.

191. Lofthus CM, Osnes EK, Falch J, Kaastad TS, Kristiansen IS, Stensvold I, Nordsletten L, Meyer HE. Epidemiology of hip fractures in Oslo, Norway. Bone 2001; 29: 413-8.

192. Tverdal A. Forekomsten av fedme blant 40-åringer i to perioder. Tidsskr Nor Lageforen 2001; 121: 667-72.

193. Tverdal A. Betydelig nedgang i blodtrykksnivå etter 1996, faktum eller artefakt? Tidsskr Nor Loegeforen 2001; 15: 1821-5.

194. Vollset SE, Refsum H, Tverdal A, Nygård O, Nordrehaug JE, Tell GS, Ueland PM. Plasma total homocysteine, cardiovascular and non-cardiovascular mortality: the Hordaland Homocysteine Study. Am J Clin Nutr 2001; 74: 130-6.

195. Tverdal A. Dødelighet av lungekreft - nå høyere hos kvinner enn hos menn under 50 år. Tidsskr Nor Lageforen 2001; 121: 2487-8.

196. Tverdal A , Nelson E. Dødeligheten i Norge av forskjellige årsaker 1951-98. SHUS-rapport nr 3/2001. Oslo: Statens helseundersøkelser 2001.

197. Meyer HE, Tverdal A, Pedersen JI, Falch JA. Factors associated with mortality after hip fracture. Osteoporosis Int 2001; 12: 517 (Response to letter by Wehren LE et al).

198. Berntsen GKR, Fønnebø V, Tollan A, Søgaard AJ, Magnus JH. Forearm bone mineral density by age in 7,620 men and women. The Tromsø Study, a population-based study. Am J Epidemiol 2001; 153: 465-73.

199. Graff-Iversen S. 40 år gamle kvinner som bruker hormonregimer - sunne utvalg eller risikogrupper? Resultater fra helseundersøkelser i 11 norske fylker 1997-99. Norsk Epidemiologi 2001; 11: 73-9.

200. Søgaard AJ, Bø K, Klungland M, Koster Jacobsen B. Norske data om fysisk aktivitet. I: Fysisk aktivitet og helse. Kartlegging. Rapport nr. 1/2001. Oslo: Statens råd for ernæring og fysisk aktivitet, 2001, s. 25-32.

201. Søgaard AJ, Tollan A, Berntsen GKR, et al. HRT: Knowledge, attitudes, and self-reported use. Menopause Digest 2001; 13: 23-6.

202. Sexton H, Søgaard AJ, Olstad R. How are mood and exercise related? Results from the Finnmark study. Soc Psychiatry Psychiatr Epidemiol 2001; 36: 348-53. 
203. Søgaard AJ. Helseatferd - Helsefremmende arbeid i konsultasjonen. I: Osteoporose. Veileder for forebygging og behandling. Oslo: Statens helseundersøkelser, 2001, s. 21-24 og 64-69.

204. Joakimsen RM, Fønnebø V, Søgaard AJ, Tollan A, Størmer J. Magnus JH. The Tromsø Study: Registration of fractures, how good are self-reports, a computerized radiographic register and a discharge register? Osteoporosis Int 2001; 12: 1001-5.

205. Graff -Iversen S, Nybø A, Skurtveit S, Bratberg Ross S. Utviklingstrender for kroppsarbeid hos norske 4042-åringer i tiden 1974 til 1994. Tidsskr Nor Lageforen 2001; 22: 2584-8.

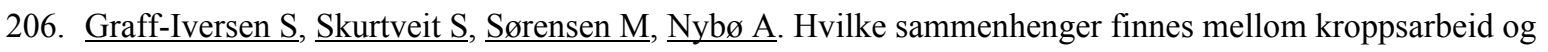
vekt? Tidsskr Nor Laegeforen 2001; 22: 2579-83.

207. Skurtveit S, Selmer R, Tverdal A. Alkoholvaner blant 40-åringer i Norge. Endring over tid. Nordisk Alkohol- \& Narkotikatidskrift 2001; 18: 296-302.

208. Glattre E, Engeland A, Jellum E, Høstmark AT. Serum-albumin and risk of thyroid cancer: A populationbased, matched case-control study. Norsk Epidemiologi 2001; 11: 197-200.

209. Tonstad S, Graff-Iversen S. Action levels for obesity treatment in 40-42 year old men and women compared with action levels for prevention of coronary heart disease. Int J Obes 2001; 25: 1698-704.

210. Dahle UR, Sandven P, Heldal E, Caugant DA. Molecular epidemiology of Mycobacterium tuberculosis in Norway. J Clin Microbiol 2001; 5: 1802-7.

211. Heldal E, Arnadottir T, Cruz JR, Tardencilla A, Chacon L. Low failure rate in standardised retreatment of tuberculosis in Nicaragua: patient category, drug resistance and survival of "chronic" patients. Int J Tuberc Lung Dis 2001; 5: 129-36.

212. Heldal E. Tuberkulose, Fugl Føniks? - ny resistens, ny epidemiologi. Medisinsk Årbok 2001: 137-146. Munksgaard forlag, København.

\section{2}

213. Meyer HE, Smedshaug GB, Kvaavik E, Falch JA, Tverdal A, Pedersen JI. Can vitamin D supplementation reduce the risk of fracture in the elderly? A randomized controlled trial. J Bone Miner Res 2002; 17: 709-15.

214. Graff-Iversen S, Tonstad S. Association of progestogen-only use with cardiovascular risk factors in 40-42year old women. Results of a population-based survey. Contraception 2002; 66: 7-13.

215. Skurtveit S, Tverdal A. Sex differences in gamma-glutamyltransferase in people aged 40-42 years in two Norwegian counties. Drug Alcohol Depend 2002; 67: 95-8.

216. Hjemmen A, Dalgard OS, Graff-Iversen S. Volden som rammer kvinner og volden som rammer menn - to ulike verdener? Norsk Epidemiologi 2002; 12: 275-80.

217. Meyer HE, Søgaard AJ, Tverdal A, Selmer RM. Body mass index and mortality: the influence of physical activity and smoking. Med Sci Sports Exerc 2002; 34: 1065-70.

218. Tverdal A, Selmer RM. 40-årings-undersøkelsene - 400000 menn og kvinner har møtt opp. Tidsskr Nor Lageforen 2002; 122: 2641-2.

219. Egeland G, Tverdal A, Meyer HE, Selmer R. A man's heart and a wife's education: A 12-year coronary heart disease mortality follow-up in Norwegian men. Int J Epidemiol 2002; 31: 799-805.

220. Diverse Population Studies Group (incl. Selmer R, Tverdal A). Prediction of mortality from coronary heart disease among diverse populations: is there a common predictive function? Heart 2002; 88: 222-8.

221. Prospective Studies Collaboration (incl. Selmer R, Tverdal A). Age-specific relevance of usual blood pressure to vascular mortality: a meta-analysis of individual data for one million adults in 61 prospective studies. Lancet 2002; 360: 1903-13.

\section{3}

222. Engeland A, Bjørge T, Selmer RM, Søgaard AJ, Tverdal A. Body mass index in adolescence in relation to total mortality; a follow-up study of 231,000 Norwegian boys and girls. Am J Epidemiol 2003; 157: 517-23.

223. Tverdal A, Skurtveit S. Coffee intake and mortality from liver cirrhosis. Ann Epidemiol 2003; 13 (6): 419 23.

224. Gulah M, Tverdal A, Selmer R, Heldal E, Bjune G. Tuberculosis in Norway by country of birth. Int J Tub Lung Dis 2003; 7 (3): 232-5.

225. Flugsrud GB, Nordsletten L, Espehaug B, Havelin LI, Meyer HE. Weight change and the risk for total hip replacement due to primary osteoarthritis. Epidemiology (akseptert). 
226. Engeland A, Bjørge T, Selmer RM, Tverdal A. Height and body mass index in relation to total mortality; a follow-up study of two million Norwegian males and females. Epidemiology 2003; 14: 293-9.

227. Engeland A, Bjørge T, Tverdal A, Søgaard AJ. Impact of obesity in adolescence and adulthood on mortality. Epidemiology (under trykking).

228. Engeland A, Tretli S, Bjørge T. Height, body mass index, and prostate cancer - a follow-up of 950,000 Norwegian men. Br J Cancer (akseptert).

229. Engeland A, Tretli S, Bjørge T. Height, body mass index, and ovarian cancer: A follow-up of 1.1 million Norwegian women. J Natl Cancer Inst 2003; 95: 1244-8.

230. Jenum AK, Lorentzen $\mathrm{C}$ on behalf of the MoRo-study group: Promoting physical activity in a multi-ethnic district - methods and baseline results of a pseudo-experimental intervention study. Eur J Cardiovasc Prevent Rehab (in press 2003).

231. The SCORE project group (incl. Selmer R, Tverdal A). Estimation of ten-year risk of fatal cardiovascular disease in Europe: the SCORE project. Eur Heart J 2003; 24: 987-1003.

232. Aires N, Selmer R, Thelle D. The validity of self-reported leisure time physical activity, and its relationship to serum cholesterol, blood pressure and body mass index. A population based study of 332,182 men and women aged 40-42 years. Eur J Epidemiol 2003; 18: 479-85. 